\title{
The effect of the ambient conditions on the life cycle of a bulbous plant
}

\author{
M. A. Jiménez ${ }^{1}$, M. A. Cerdà ${ }^{2}$ and J. Rita ${ }^{2}$ \\ ${ }^{1}$ Department of Global Change Research, Mediterranean Institute for Advanced Studies IMEDEA (CSIC-UIB), Miquel \\ Marquès 21, 07190 Esporles, Illes Balears \\ ${ }^{2}$ University of the Balearic Islands, Palma de Mallorca, Illes Balears \\ Received: 10-XII-2013 - Accepted: 1-V-2014 - Original version
}

Correspondence to: majimenez@imedea.uib-csic.es

\begin{abstract}
To evaluate how weather conditions affect the life cycle of a bulbous plant species, a methodology is proposed here using Crocus cambessedesii, a plant that is endemic to Mallorca and Menorca. Data from an experimental field study conducted from 2007 to 2013 in the south west of Mallorca is taken together with meteorological observations from Palma Airport, located about $10 \mathrm{~km}$ away from the site. The bias in the observations between the Airport and the field site is discussed, as well as the importance of performing meteorological measurements in situ to have a better knowledge of the local processes. It is found that flowering and fruiting periods start when the mean temperature is between the range of $16-20^{\circ} \mathrm{C}$ and $10-14^{\circ} \mathrm{C}$, respectively. In addition, a certain amount of soil water content is needed (it has been raining during the previous days). These results are in agreement with those obtained for Crocus sativus, extensively studied for economic interests. Finally, some recommendations are made to apply this methodology to plants in other locations or other species.
\end{abstract}

Key words: Crocus cambessedesii, flowering and fruiting periods, soil water content, local temperature, representativeness of a surface station

\section{Introduction}

Ambient conditions strongly influence the life cycles of most organisms. Particularly, the reproduction, photosynthesis, leaf fall or flowering and fruiting periods of the plants can be delayed, advanced or shortened in time depending on the environmental factors such as temperature or rain. Phenology is a branch of ecology that studies the relation between the ambient conditions and the biologic phenomena that occur periodically associated to rhythms of the seasons. Several studies have been performed in order to evaluate the phenology of different plants. For instance, the climatology analysis of Peñuelas et al. (2002) showed that the flowering and fruiting periods in Cardedeu (NE of the Iberian peninsula) were earlier in 2000 than in 1952, whereas the leaf fall was delayed. This was related to a change in the temperature and precipitation during the 1952-2000 period. Similarly, Lobell et al. (2007) studied the effect of the temperature and the precipitation on California crops from 1980 to 2003. They found that the amount of production of some crops, such as grapes or almonds, was very much affected by the precipitation.

In this work, the attention is focused on geophyte plants, which are herbaceous and perennial plants with an underground nutrient reserve organ. It allows them to survive in unfavourable weather periods (von Willert et al., 1992) while they lose the aerial part. When the environmental conditions become favourable, the underground reserves allow these plants a new cycle of growing. The phenology of geophytes can be modelled with suitable meteorological parameters, mainly those related to the temperature (Eppich et al., 2009).

As an example of geophyte plants, Crocus cambessedesii is studied in this work (Figure 1). The genus Crocus, from the Iridaceae family, has more than one hundred species, a lot of them of ornamental interest and others exclusively wild (Harpke et al., 2013). In the Spanish flora there are six species of Crocus plus the cultivated Cro- 


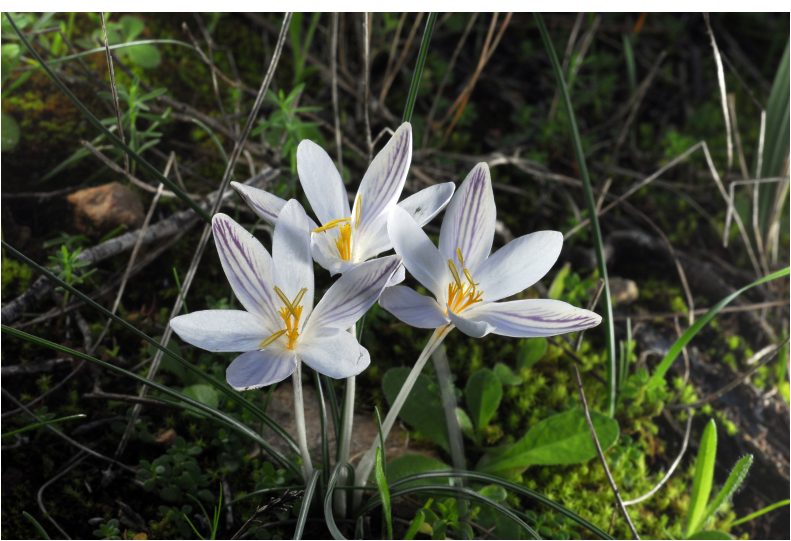

Figure 1. An example of Crocus cambessedesii in the field site where observations are conducted.

cus sativus, four of them (including Crocus cambessedesii and Crocus sativus) bloom in autumn and the other three species in spring (Pastor-Férriz et al., 2013). As an example, Crocus sativus is one of the most appreciated in the kitchen and in medicine, because it is the source of saffron. Spain is the main world producer of saffron and it is processed and exported as a specie around the world (Mathew, 1984). Due to its commercial interest, a lot of studies about its life cycle have been performed (Negb et al., 1989; Molina et al., 2004, 2005).

Crocus cambessedesii is a plant that is endemic to Mallorca and Menorca (Alomar et al., 1997; Rosselló and Castro, 2008), typically found in a large variety of ambient conditions: in rock fissures near the coast or on mountain slopes, and less frequently in open areas of Olea europaea scrubland and Pinus halepensis forests, as seen in PastorFérriz et al. (2013). This plant has a corm as its subterranean storage organ (here we use the term bulbous in a very broad sense) which has a tunic with parallel and vertical fibers; their leaves are very narrow, about $1 \mathrm{~mm}$ wide and up to $15 \mathrm{~cm}$ long, with a white central stripe along the leaf axis. Flowers and leaves appear at the same time directly from the corm and it looks as if the flowers emerge from the soil. The flowers are $5-8 \mathrm{~cm}$ tall, with six subequal white or pale lilac tepals with prominent purple stripes on their external part. They have three stamens with yellow anthers and the style has three reddish-orange divided stigmatic branches (Figure 1).

The main objective of this work is to study how the ambient conditions affect the flowering and fruiting periods of Crocus cambessedesii. Observations from an experimental field study conducted from 2007 to 2013 are used, together with meteorological data from an automatic surface weather station close to the field site belonging to the Spanish Meteorological Agency (AEMET). Studies involving biological and meteorological processes are difficult due to the lack of knowledge of the biological processes and their non-lineal response to the environ-
Table 1. Description of the stages during the fruiting period of Crocus cambessedesii according to the size of the fruit.

\begin{tabular}{lc}
\hline $\begin{array}{l}\text { Fruiting } \\
\text { stages }\end{array}$ & Characteristics \\
\hline 0 & no fruit \\
1 & fruit around several millimetres above the ground \\
2 & fruit around several centimetres above the ground \\
3 & the capsule is growing but it is not mature \\
4 & fruit is mature \\
C & fruit is collected \\
\hline
\end{tabular}

ment. However, understanding this relation is important for economic reasons (profitability of a harvest) or for knowing the ability of a plant to live under extreme ambient conditions (adaptation to the climate change), among others.

The paper is organized as follows. Data used are explained in section 2, whereas sections 3 and 4 are devoted to the analysis of the flowering and fruiting periods, respectively. The discussion of the results is done in section 5 where they are compared to those obtained for Crocus sativus. Finally, the conclusions are given in section 6.

\section{Data used and period of interest}

\subsection{Field measurements}

During 2007-2013 an experimental field study took place in a flat elevated area in the south west of Mallorca (see location in Figure 2 with a black dot). This area is about $120 \mathrm{~m}$ above sea level in a protected natural area with a large variety of endemic plants. The main objective of the experimental field study was to further inspect the plant life cycle of Crocus cambessedesii. Weekly observations were conducted from September to November and from February to March, corresponding to the flowering and fruiting periods, respectively.

We selected a sample of 30 individuals, which is a usual sample size in phenology studies (Blionis et al., 2001; Debussche et al., 2004; Morin et al., 2009), and each plant was marked when the floral buds started to emerge from the soil. It was considered that the flowering started when any of the 30 randomly selected plants started to bloom in the field site and it finished when the flowers on the plant had withered. Since the observations were weekly, these dates might have an error of up to about 4-5 days. The same methodology was considered for the fruiting period. During 2013, the fruiting period was further studied and every week the 30 randomly selected plants were classified in 6 stages depending of the size of the fruit, as seen in Table 1 . Stage 0 corresponds to no fruit, whereas in stage $\mathrm{C}$ the fruit is collected for a further laboratory analysis. It was found that the fruit is a capsule 
Table 2. Statistics computed from the period January 2008 to May 2013 for different automatic surface weather stations of the AEMET network (see locations in Figure 2). In parenthesis the temperature at the Airport corrected by the elevation $\left(0.65^{\circ} \mathrm{C} / 100 \mathrm{~m}\right)$ and considering that it is about $110 \mathrm{~m}$ of altitude below the stations over the plateau. The bias is referred to the Airport station.

\begin{tabular}{cccc}
\hline & Location & Mean value & Mean bias \\
\hline \multirow{3}{*}{$T_{\text {mean }}\left({ }^{\circ} \mathrm{C}\right)$} & Airport & $15.6(14.9)$ & - \\
& Llucmajor & 15.8 & 0.2 \\
& Cap Blanc & 16.4 & 0.8 \\
& Airport & $21.1(20.4)$ & - \\
$T_{\text {max }}\left({ }^{\circ} \mathrm{C}\right)$ & Llucmajor & 20.8 & -0.1 \\
& Cap Blanc & 20.4 & -0.5 \\
& & & \\
& Airport & $10.1(9.4)$ & - \\
$T_{\text {min }}\left({ }^{\circ} \mathrm{C}\right)$ & Llucmajor & 10.9 & 1.1 \\
& Cap Blanc & 12.3 & 2.5 \\
& & & \\
Precipitation & Airport & 0.69 & - \\
$($ mm day & Llucmajor & 0.70 & 0.01 \\
& Cap Blanc & 0.60 & -0.13 \\
\hline
\end{tabular}

and it produces up to 26 seeds but only an average of about $60 \%$ are viable.

\subsection{Meteorological observations}

In the field site, there are no atmospheric measurements but there are three automatic surface weather stations from the AEMET network in the surroundings. Llucmajor and Es Cap Blanc (labelled as $L L$ and $C B$ in Figure 2) are in the plateau where the experimental field study took place, but located at $4 \mathrm{~km}$ and $10 \mathrm{~km}$ away, respectively, to the $\mathrm{NE}$ and SW. Neither of them cover the 2007-2013 period and they are not very representative of the field conditions. Llucmajor is located inside the town of Llucmajor and Es Cap Blanc is about $700 \mathrm{~m}$ away from a cliff and very much influenced by the sea. Therefore, data from the Airport, about $10 \mathrm{~km}$ away from the field to the $\mathrm{W}$, was taken.

From high-resolution mesoscale simulations, the $1.5 \mathrm{~m}$ temperature in the field (a dot in Figure 2) is about $1 \mathrm{~K}$ colder than in the Airport (labelled as $A$ in Figure 2a) during the day and about $2 \mathrm{~K}$ warmer during the night (Figure $2 b)$. This is in agreement with a similar case described in Cuxart et al. (2007) or in Jiménez et al. (2008) through satellite-derived land-surface temperatures. This bias in the temperature can be related to the fact that the Airport is located at an altitude of about $110 \mathrm{~m}$ below the site where the measurements are taken (in the plateau, see Figure 2). Considering a linear decrease of the temperature with height of $0.65^{\circ} \mathrm{C} / 100 \mathrm{~m}$ in the Airport, the differences in the elevations of the Airport and the field site would explain that the temperature in the field site is about $0.7^{\circ} \mathrm{C}$ colder than at the Airport.
Besides, the physical mechanisms that take place over the plateau and in the center of the Palma basin are not the same and they can help to explain the temperature differences, specially under weak wind conditions. Cuxart et al. (2007) found that during night-time, the air flows down the slopes and accumulates in the center of the Palma basin (where the Airport is placed) and a cold pool is formed. Cold pools are not formed over the plateau but the local heterogeneities (different soil uses or small topographical depressions among others) induce different nocturnal coolings over this flat area (Figure 2b), as was found in Martínez et al. (2010), for the Duero river basin. During the day, the Palma basin is influenced by the sea breeze from May to October that it is enhanced by the mountain slopes that close the Palma basin (Cuxart et al., 2014). Once the sea breeze is set, the $1.5 \mathrm{~m}$ temperature in the center of the Palma basin stops warming whereas over the plateau, the radiative warming continues until the afternoon.

To quantify the bias between the plateau (field site and surface stations $L L$ and $C B$ ) and the center of the basin (surface station $A$ ) in Figures $2 \mathrm{c}$ and $2 \mathrm{~d}$, the monthly maximum and minimum temperatures for the three locations are compared from January 2008 to May 2013. The corresponding mean values computed over this period are shown in Table 2, together with the bias considering the Airport as a reference.

Figures $2 \mathrm{c}$ and $2 \mathrm{~d}$ show that the largest differences between the Airport and the stations in the plateau are in winter and in summer time whereas during the rest of the year the temperatures for the three surface stations are similar.

During the day, the averaged maximum temperature at the Airport $\left(20.4^{\circ} \mathrm{C}\right.$, corrected by the altitude) is the same as in Es Cap Blanc, whereas it is $0.4^{\circ} \mathrm{C}$ colder than in Llucmajor, a location less influenced by the sea. Due to the fact that the surface station of Llucmajor is located inside the town, the urban heat island might explain the warmer maximum temperatures in Llucmajor than in the rest of the stations (Es Cap Blanc and the Airport once the temperature is corrected by the altitude). During the night, the coldest minimum temperatures of the Airport are related to the nocturnal strong cooling of the centre of the Palma basin (cold pool formation). This results in a negative temperature bias during the day and positive and large during the night (Table 2). Regarding the precipitation, there are no significant differences between the three surface stations (small bias in Table 2).

To sum up, it is appropriate to use data from the Airport to represent the weather conditions in the field site, but considering a bias of about $-0.2^{\circ} \mathrm{C}$ and $2^{\circ} \mathrm{C}$ for the maximum and minimum temperatures, respectively, with approximately the same amount of precipitation.

\subsection{Observational period}

In order to better characterize the flowering and fruiting periods, in Figure 3 the winter (December, January, Febru- 

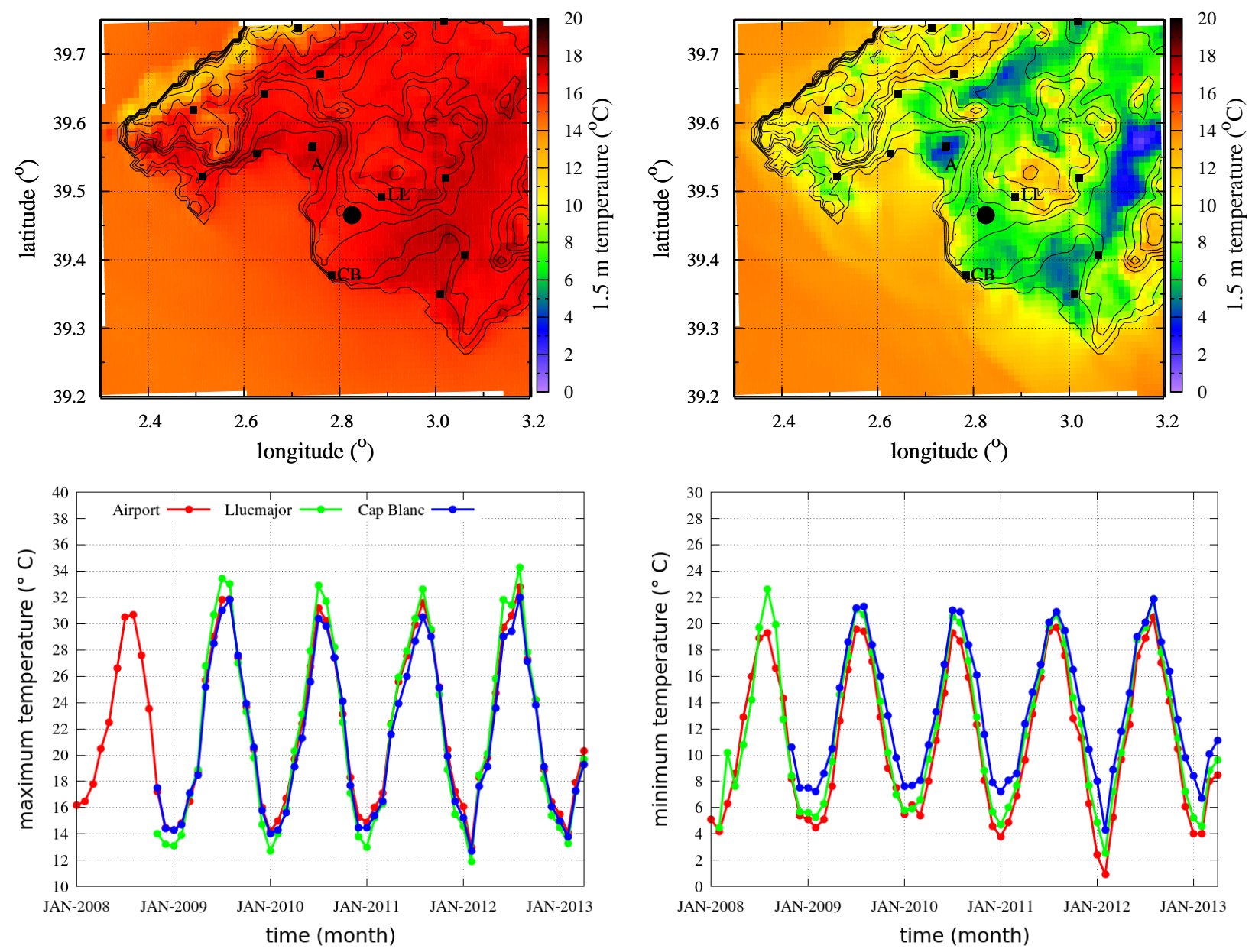

Figure 2. (a, top left) Simulated $1.5 \mathrm{~m}$ temperature at 1230 UTC on 28th January 2008, together with the topography (lines). The squares indicate the location of the automatic surface weather stations from the AEMET network. The field where the observations of Crocus cambessedesii are conducted is indicated with a black dot. The same in (b, top right) for 29th January 2008 at 0200 UTC. (c, bottom left) Monthly averages of the maximum temperature observed in Palma Airport, Llucmajor and Es Cap Blanc (labelled as $A, L L$ and $C B$ in the maps above). The same in ( $\mathrm{d}$, bottom right) for the minimum temperature.

ary) and autumn (September, October, November) averages are computed for 2007-2013 for the mean, maximum and minimum temperatures and the accumulated precipitation at the Airport. The horizontal line indicates the corresponding climatology values (1972-2000).

It is found that the coldest falls were in 2007 and 2010 and the warmest during 2009 and 2011, according to the averaged mean, maximum and minimum temperatures during the 1972-2000 period. However, the precipitation during fall was greater than the climatology value (Figure $3 b$ ) and it was more variable during winter. There are some years with larger or smaller values than the climatological ones, indicating humid and dry periods, respectively.

Furthermore, this classification agrees with the seasonal bulletins (available on the AEMET website) over Mallorca that are made considering all the automatic surface observations of the AEMET network. Therefore, the characteristics of the seasons found in Figure 3 are also valid for the region where the experimental field study took place.

\section{The ambient conditions that favour the flower- ing period}

The ambient conditions during the measured flowering periods (2007-2013) are analysed using daily temperatures (mean, maximum and minimum) and the precipitation. Figure 4 shows the temporal evolution of the daily mean temperature and accumulated precipitation for 2007 and 2009, as an example of cold and warm falls, respectively (according to Figure 3). The measurement at the beginning of the flowering period for each of the two years considered is also included in the plot (vertical line).

It is found that the flowering period starts when the daily mean temperature has decreased about $10^{\circ} \mathrm{C}$ in comparison 

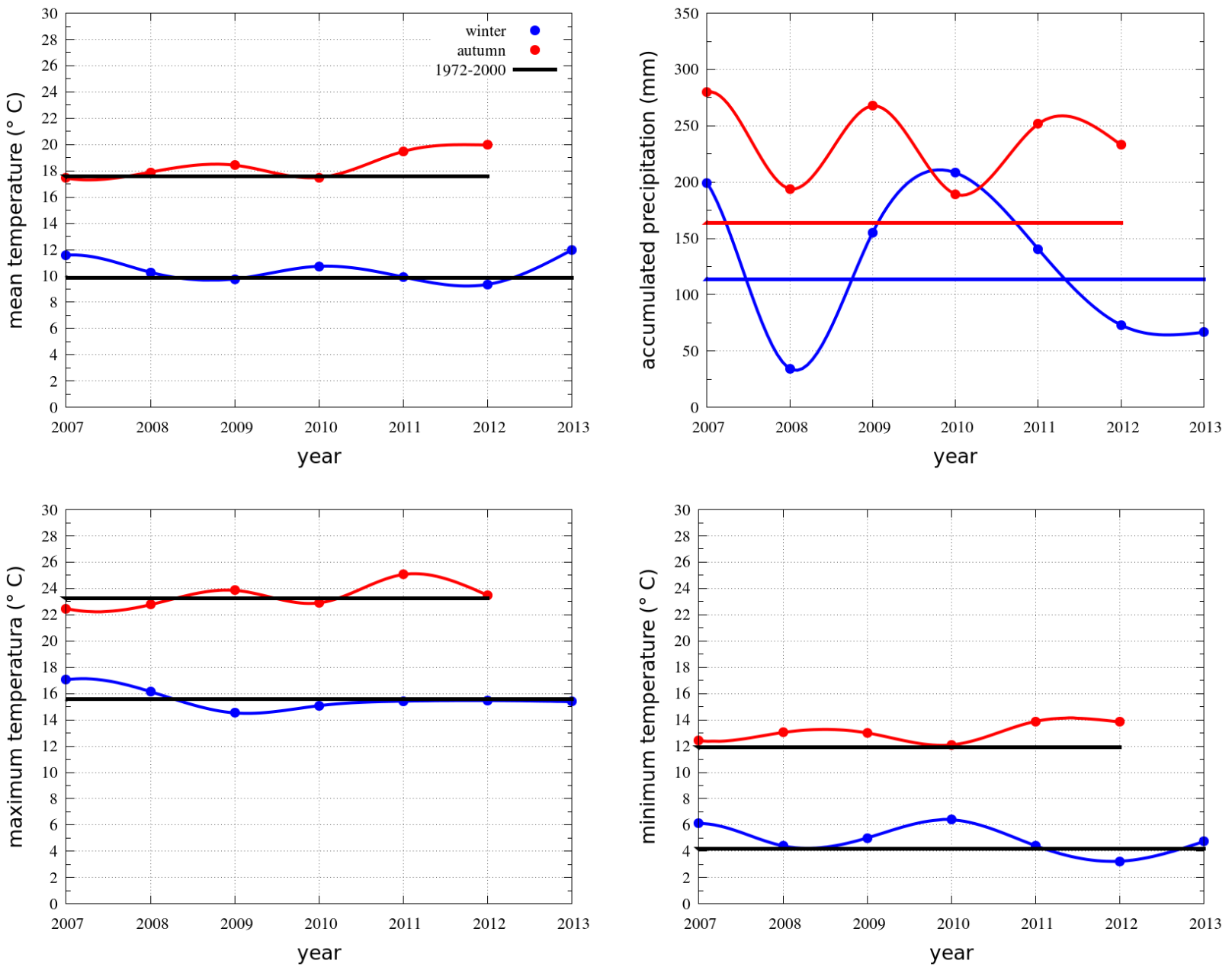

Figure 3. Winter time (December, January, February in blue) and autumn (September, October, November in red) averages during 2007 to 2013, together with those over the 1972-2000 period (horizontal lines), computed from daily values of: (a, top left) mean temperature, (b, top right) accumulated precipitation, (c, bottom left) maximum temperature and (d, bottom right) minimum temperature.

to the summer values (Figure 4a). However, it starts 24 days earlier in 2009 than in 2007, indicating that the temperature is not the only relevant parameter. Figure $4 \mathrm{~b}$ shows that the flowering period starts after a period of rain followed by several days without rain, for both selected years. Thus, Crocus cambessedesii needs a certain quantity of humidity at ground level to initiate the flowering period.

In Figure 5 data during the whole experimental field study are considered. Weekly averages of the daily mean temperature and the accumulated precipitation are taken to better compare these years. Also, the X-axis has been normalized by the initiation of the flowering period measured in the field. As Lobell et al. (2007) pointed out, monthly values certainly mask extremes that might be important to the harvest. To keep the daily extremes as much as possible and to have a smoother time series, weekly averages are considered, with the same temporal interval as the field measurements.

During all the years, flowering starts when the mean temperature decreases $4-6^{\circ} \mathrm{C}$ in comparison to the summer values. Besides, $T_{\text {mean }}=16-20^{\circ} \mathrm{C}, T_{\text {maximum }}=22-26^{\circ} \mathrm{C}$ and $T_{\text {minimum }}=12-16^{\circ} \mathrm{C}$, considering weekly averages. It is also found that the flowering period starts about 10-30 days after rainy days (Figure $5 b$ ), depending on the intensity of the rain (the more rain, the later the flowering starts). Thus, a certain quantity of soil water content is needed for actual evapotranspiration and normal metabolic activity although the terrain cannot be waterlogged. The lack of precipitation in the previous days may also be important and it is also a triggering factor for flowering in many species.

In order to quantify the relation between the duration of the flowering period and the ambient conditions, linear regressions are computed in Figure $5 \mathrm{c}$. The parameter $\Delta \mathrm{T}=T_{\text {initial }}-T_{\text {final }}\left(T_{\text {initial }}\right.$ and $T_{\text {final }}$ are the weekly averaged mean temperatures at the beginning and ending of the flowering period, respectively) is used to evaluate whether there is a relation between the temperature and the duration of the flowering period. It is found that the longer flowering period does not always correspond to the larger 

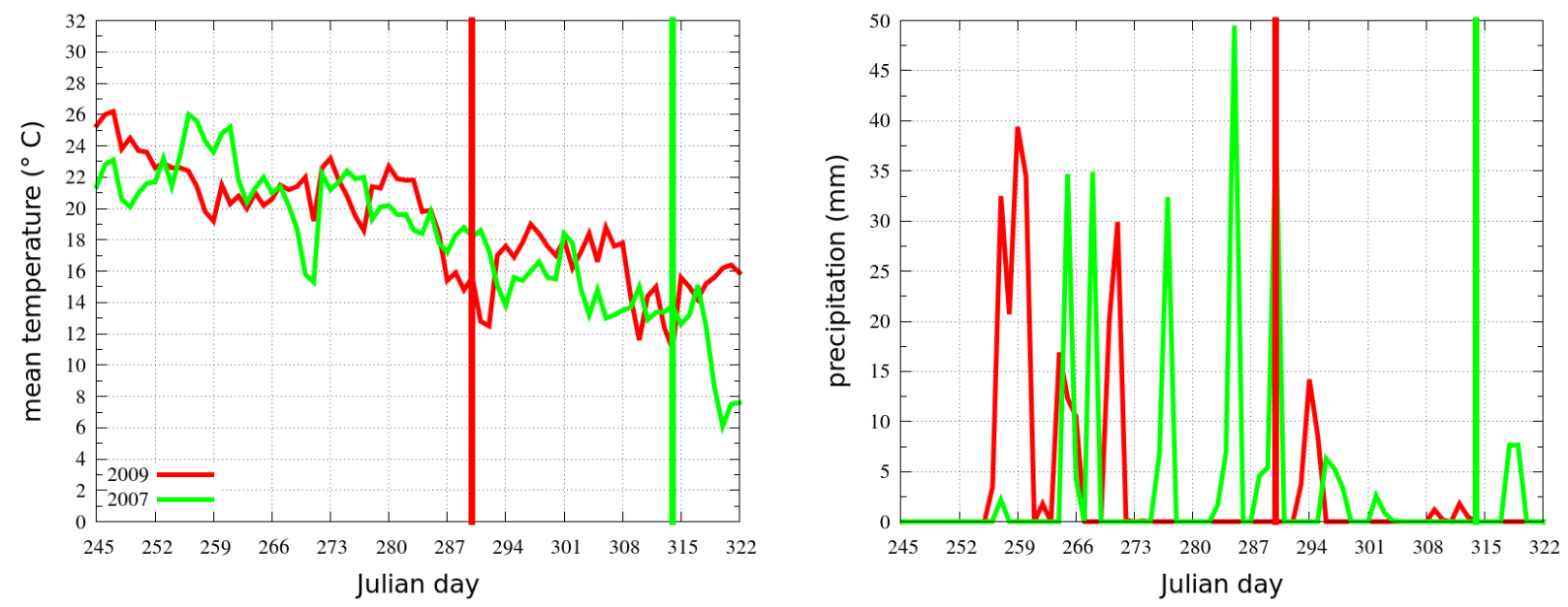

Figure 4. Daily values of (a, left) mean temperature and (b, right) precipitation from 1st September to 18 th November (Julian day from 245 to 322). 2007 and 2009 are taken as an example of cold and warm autumns, respectively, according to Figure 3 . The vertical lines indicate the day when flowering started for each year.

$\Delta \mathrm{T}$ (Figure $5 \mathrm{c}$ in blue, $r^{2}=0.13$ and $p=0.55$ ). Regarding the accumulated precipitation, Figure $5 \mathrm{c}$ (in red) shows that it is better correlated with the duration of the flowering period (coefficient of determination $r^{2}=0.35$ and statistical significance $p=0.29$ ) than the temperature parameter, although the correlation and the statistical significance are still weak. Therefore, in some years, the longer flowering period might correspond to the greater accumulated precipitation.

It is important to mention that the duration of the flowering period is computed for the whole plant population. Thus, the plants are more synchronised during the years with short flowering periods (all the plants start flowering at nearly the same time) and less synchronised during the years of longer flowering periods. Severe weather conditions (for instance rain) might be responsible for losing the synchronism between the plants of a field, but further field measurements are needed to properly determine the reasons.

\section{The ambient conditions that favour the fruiting period}

A similar analysis as the one explained in the previous section is made for the fruiting period.

Figure 6 shows the time series of the daily mean temperature and precipitation for 2010 and 2012, as an example of a warm and cold winter, respectively (Figures $3 \mathrm{a}, 3 \mathrm{c}$ and 3d), and 2008 and 2010 as an example of dry and wet winters, respectively (Figure 3b). For all the years, the fruiting period starts nearly at the same time. This happens when the temperature has increased around $1-4^{\circ} \mathrm{C}$ with respect to the winter values (Figure 6a). The precipitation is again a triggering factor since the fruiting period starts after some rainy events (Figure 6b) and when there is enough soil water con- tent. Therefore, the fruiting period starts later in the driest year (2008).

If observations of the whole experimental field study are considered (Figure 7), it is found that the fruiting period starts when $T_{\text {mean }}=10-14^{\circ} \mathrm{C}, T_{\text {maximum }}=13-18^{\circ} \mathrm{C}$ and $T_{\text {minimum }}=2-8^{\circ} \mathrm{C}$, considering the weekly averages. All the years follow a similar pattern although the fruiting period starts with a difference of 30 days between the year that starts the earliest (February 11th, 2013) and latest (March 11th, 2008).

The effect of the ambient conditions on the duration of the fruiting period is evaluated in Figure 7c. It is found that the accumulated rain is a key factor to determine the duration of the fruiting period (lineal regression with $r^{2}=0.87$ and $p$ $=0.021$ ). As a result, when there is more rain, the fruiting period is longer and the plant synchronism is reduced. However, the mean temperature has no correlation with the duration of the fruiting period $\left(r^{2}=0.005\right.$ and $\left.p=0.907\right)$. This might indicate that the temperature is more steady during the fruiting period (end of February and beginning of March) than during flowering (end of October and beginning of November).

\subsection{Evolution of the fruit growth}

During the fruiting period of 2013, weekly observations of the percentage of plants in each of the stages of Table 1 were performed. The temporal evolution of these percentages is shown in Figure 8. As time advances, the percentage of plants with higher stages increases while the percentage of plants with lower stages decreases. Stage 2 is the longest, indicating that once the fruit appears it is around several centimeters above the ground for about 4 weeks. Afterwards, the growing (stage 3, 2.5 weeks) and mature stages (stage 4, 2 weeks) are shorter. 

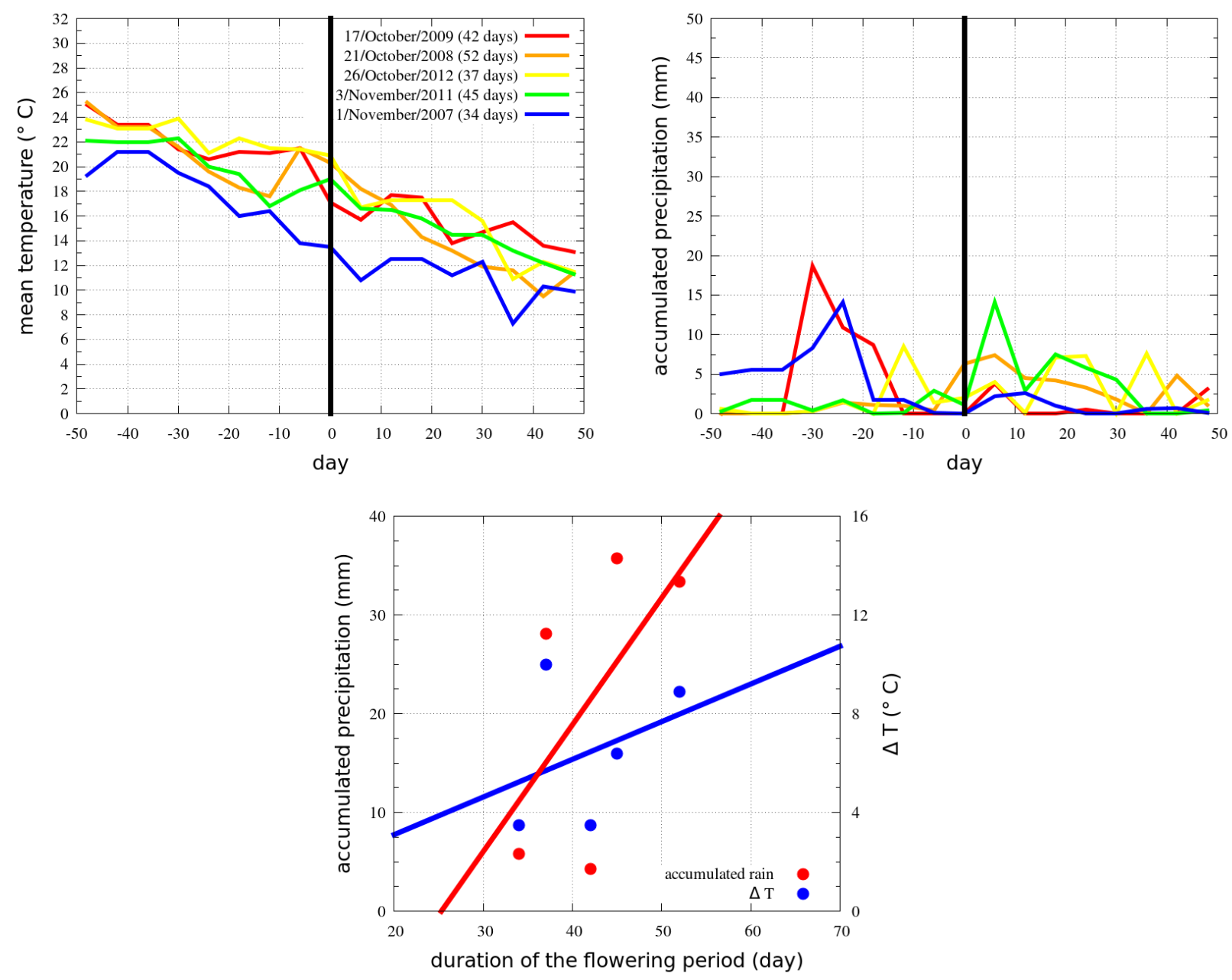

Figure 5. Weekly mean values of (a, top left) daily mean temperature and (b, top right) precipitation when the field measurements have been conducted, for 50 days before and after the initiation of the flowering (indicated with a black vertical line). The measured day of the initiation of the flowering and its corresponding duration (in parenthesis) for the years studied is shown in the top right corner in (a). (c, bottom) Correlation between the duration of the flowering period and the accumulated precipitation during those days (in red) and the temperature difference $\left(\Delta \mathrm{T}=T_{\text {initial }}-T_{\text {final }}\right.$, in blue, where $T_{\text {initial }}$ and $\left.T_{\text {final }}\right)$ are the weekly averaged mean temperatures during the beginning and ending of the flowering period, respectively.

The evolution of the mean temperature and the precipitation is also included in this plot. The increase in the percentage of plants in stages 3 and 4 is simultaneous to an increase in the daily mean temperature (Figure 8a). A similar pattern is found for the precipitation (Figure 8b). This might indicate that the plant needs a certain quantity of soil water and warm temperatures for the maturing of the fruit.

This type of plot is useful to check how the ambient conditions affect the temporal evolution of the different stages of the fruiting period. However, these observations were only made during 2013 and more measurements are needed to reach a more general conclusion.

\section{Discussion}

A summary of the temperature ranges found during the fruiting and flowering periods is shown in Table 3. The Airport temperatures are corrected with a mean bias of $+0.5^{\circ} \mathrm{C},-0.3^{\circ} \mathrm{C}$ and $+2.0^{\circ} \mathrm{C}$ for the mean, maximum and minimum temperatures derived from Table 2 to have an estimation of these ranges at the field site.

Table 3 shows that the temperatures obtained for Crocus cambessedesii are similar to those derived in Molina et al. (2005) for Crocus sativus through laboratory experiments. The field experiments with Crocus sativus carried out in Geracello (Sardinia, Italy) and Capitone (Abruzzo, Italy) by Gresta et al. (2009) showed that the precipitation was also 

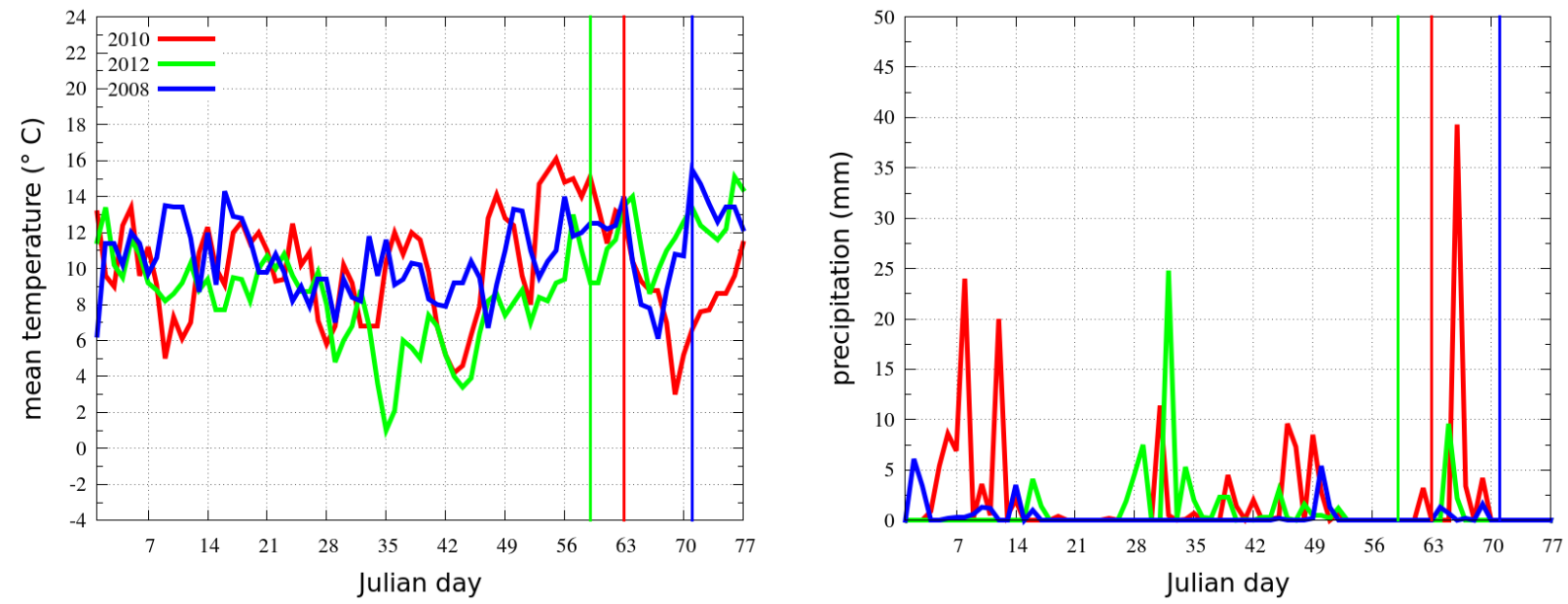

Figure 6. The same as Figure 4 but during the fruiting period. 2010 is taken as an example of a warm, dry winter, 2012 as a cold winter and 2008 as a dry winter, according to Figure 3.
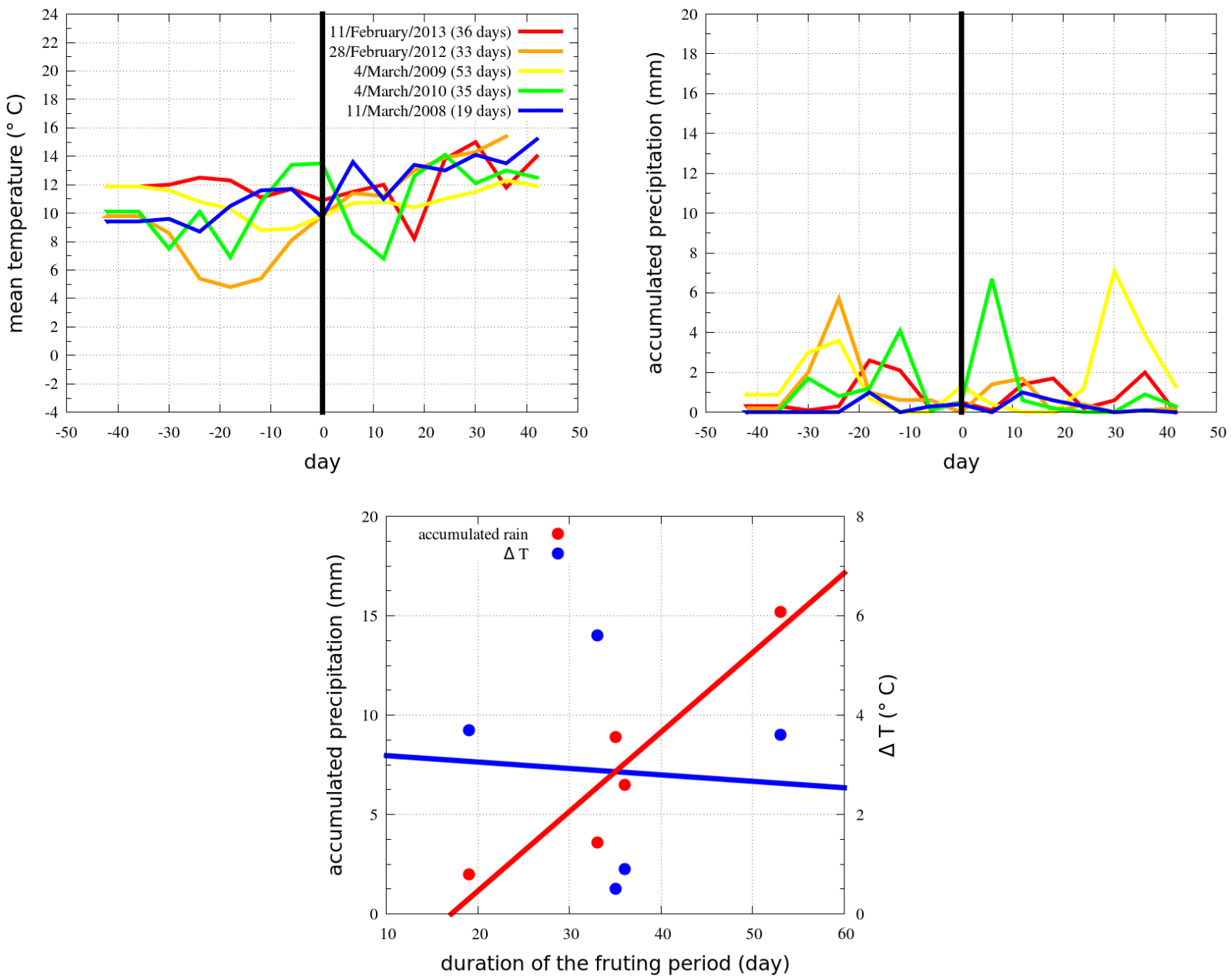

Figure 7. The same as Figure 5 but during the fruiting period. 

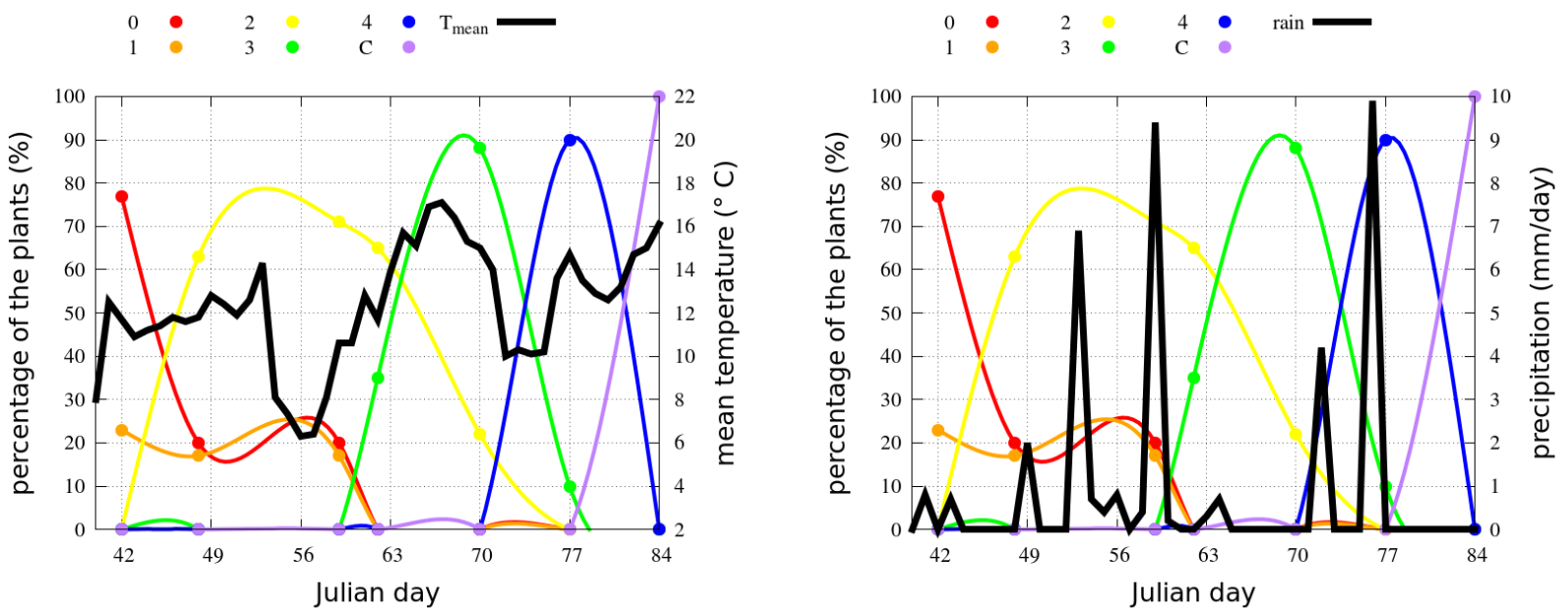

Figure 8. Evolution of the percentage of different fruiting stages (described in Table 1) measured from 11th February (Julian day 42) to 25th March 2013 (Julian day 84) together with the evolution of some meteorological variables (thick black line): (a, left) mean temperature and (b, right) precipitation.

Table 3. Optimal temperature ranges computed from the automatic surface weather station at the Airport (see location in Figure 1) when the fruiting and flowering of the Crocus cambessedesii are measured in the field (2007 - 2013 period). These values are weekly averaged and they are extracted from Figures 5 and 7 . The temperature at the field site is indicated in parenthesis, considering a mean bias of $+0.5^{\circ} \mathrm{C}$, $-0.3^{\circ} \mathrm{C}$ and $+2.0^{\circ} \mathrm{C}$ for the mean, maximum and minimum temperatures obtained from Table 2 . The temperature ranges of the flowering period of Crocus sativus obtained by Molina et al. (2005) are also included in bold.

\begin{tabular}{lcc}
\hline & $\begin{array}{c}\text { Flowering period } \\
\text { (October-November) }\end{array}$ & $\begin{array}{c}\text { Fruiting period } \\
\text { (February-March) }\end{array}$ \\
\hline$T_{\text {mean }}\left({ }^{\circ} \mathrm{C}\right)$ & $16-20(16.5-20.5)$ & $10-14(10.5-14.5)$ \\
& $22-26(21.7-25.7)$ & $13-18(12.7-17.7)$ \\
$T_{\text {max }}\left({ }^{\circ} \mathrm{C}\right)$ & $\mathbf{2 3 - 2 7}$ & - \\
Molina et al. (2005) & & \\
& $12-16(14.0-18.0)$ & $2-8(4.0-10.0)$ \\
$T_{\text {min }}\left({ }^{\circ} \mathrm{C}\right)$ & $<\mathbf{1 7}$ & - \\
Molina et al. $(2005)$ &
\end{tabular}

a key parameter to trigger the flowering, apart from the temperature. They found that once the temperature range is adequate for the initiation of the flowering, a certain soil water content is needed (it has rained some days before), in agreement with our findings (Figure 5). However, hydric stress is a known flowering trigger mechanism in many species (for instance, the Arabidopsis described in Ausín et al., 2005, or in tropical trees discussed by Sakai et al., 2006) and this fact might explain the loss of synchronism between plants when there is more rain and the flowering period is longer (Figure 5c).

Similar results are found for the fruiting period (Figure 7). It starts when the winter temperatures warm up to a certain range (Table 3 ) and there is enough soil water content (it has been raining a few days before). Figure 7c also shows that the precipitation is a key parameter to determine the duration of the fruiting period (the more rain, the longer the period) related to a loss of synchronism between plants.
Other meteorological parameters might have been considered to properly describe when the flowering/fruiting periods start. It is important to take into account that the height of Crocus cambessedesii is a few centimeters above the ground and it is typically surrounded by other taller plants (Figure 1). Thus, it is expected that the wind speed or direction might not have a big impact on the flowering/fruiting period. Giving that Crocus cambessedesii is very close to the ground, the key parameter would be the ground temperature, rather than the $1.5 \mathrm{~m}$ or $2 \mathrm{~m}$ temperature (these are the heights where automatic surface weather stations are placed in most meteorological networks). This highlights the importance of not only having meteorological measurements in the field site of temperature and precipitation (as in other surface stations) but also measurements of the ground temperature and the soil moisture to properly evaluate the impact of the ambient conditions on the life cycle of Crocus cambessedesii. 

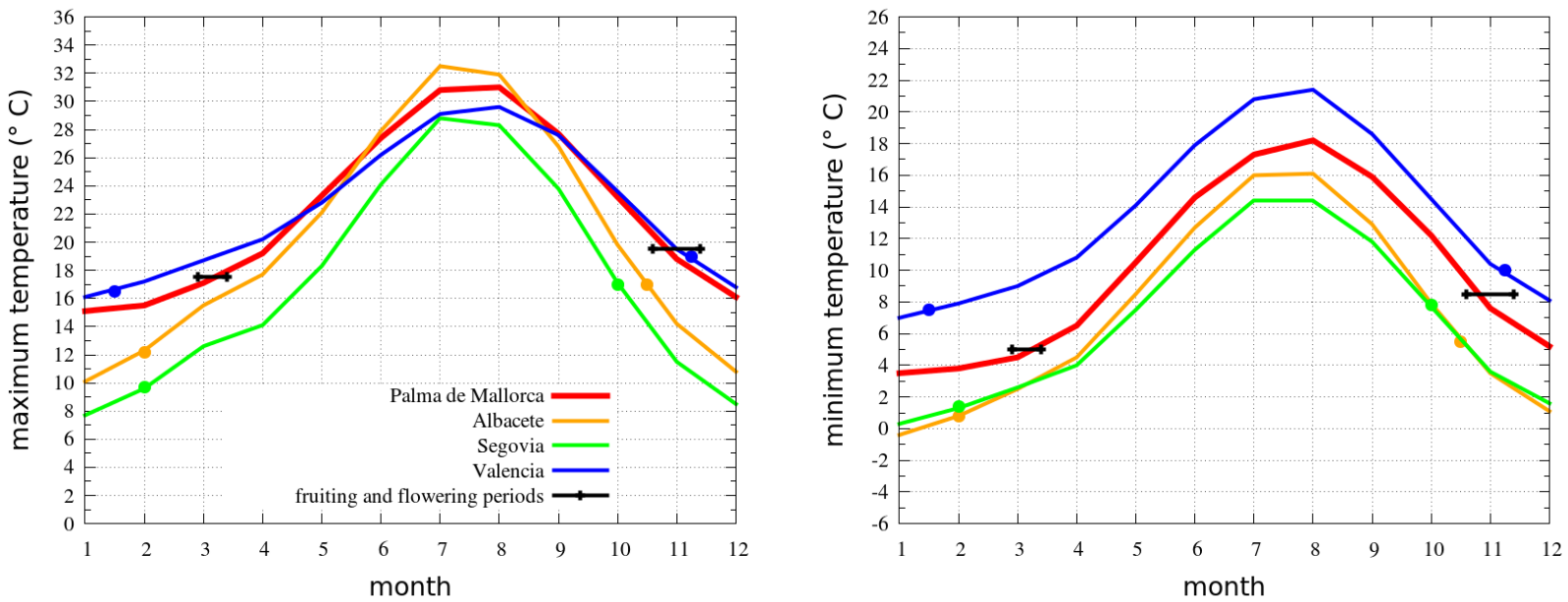

Figure 9. Monthly averaged temperatures (1971-2000) at Palma Airport (red line) with the period of the observed days when fruiting and flowering has started (black line): (a, left) maximum temperatures and (b, right) minimum temperatures. The same is shown for Albacete, Segovia and Valencia with the measurements of fruiting and flowering periods from Molina et al. (2005).

Another important issue about Crocus cambessedesii is that it can be found in many places in Mallorca (near the coast, on the mountain or in flat areas) with different soil properties and different weather conditions (Figure 2). Thus, the flowering/fruiting periods might be advanced or delayed depending on the temperature ranges and the precipitation of each site.

Figure 1 of Molina et al. (2005) showed that the plant cycle of Crocus sativus depends on the ambient conditions. Figure 9 is shown here with their data together with our findings with Crocus cambessedesii. During fall (October or November) the flowering period starts when the maximum and minimum temperatures are within the intervals of Table 3 in agreement with Molina et al. (2005). However, the day when the flowering period starts changes depending on the locations. In the places with more continental climates (with colder temperatures as in Segovia and Albacete), the flowering period starts earlier than in the places with a more temperate climates (such as Valencia or Palma). The values for the fruiting period are more spread. The maximum temperature can be from $10^{\circ} \mathrm{C}$ to $18^{\circ} \mathrm{C}$ and the minimum from $1^{\circ} \mathrm{C}$ to $8^{\circ} \mathrm{C}$. This results in a time difference of about 2 months between the fruiting in the different sites. It is important to keep in mind that in Figure 9 results from Crocus sativus are compared to those from Crocus cambessedesii and some of the differences might be explained because they are different species.

\section{Conclusions}

A methodology is proposed to evaluate the effect of the weather conditions on the flowering and fruiting periods of Crocus cambessedesii, a bulbous plant species endemic to
Mallorca and Menorca. However, the analysis can be easily extended to other plants.

It is found that the ranges of temperature when the flowering and fruiting periods start are similar to those obtained in Molina et al. (2005) through laboratory experiments with Crocus sativus. Apart from the temperature, the amount of soil water content is a triggering factor as found in Gresta et al. (2009). Thus, observations indicate that the initiation of the flowering and fruiting periods is after a period of rain. If the precipitation is intense, some days are needed to evaporate or infiltrate the water at ground level before the initiation of the flowering and fruiting. Besides, the results show that the amount of precipitation will determine the duration of those periods (synchronism of the plants in a field).

Considering that Crocus cambessedesii is found in different places (from the coast to the mountains) over the island of Mallorca, the starting of the flowering and fruiting periods can be earlier or later than those obtained here. The local weather conditions will also determine the duration of these periods.

Finally, it is important to highlight that to properly study how the ambient conditions affect the evolution of Crocus cambessedesii or other kinds of plants, atmospheric measurements at the field site must be carried out. Since Crocus cambessedesii has a height of a few centimetres above ground level, the surface temperature and the soil moisture are more relevant to understand the life cycle, rather than the parameters classically observed by a surface station (1.5 $\mathrm{m}$ temperature and precipitation, among others).

Acknowledgements. The authors are extremely grateful for the suggestions made by the anonymous reviewers and J. Cuxart (Universitat de les Illes Balears) and also the Spanish Meteorological 
Agency (AEMET) for providing data from the automatic weather stations. M.A. Jiménez acknowledges the financial support from JAE-Doc program (CSIC, co-funded by the ESF).

\section{References}

Alomar, G., Mus, M., and Rosselló, J. A., 1997: Flora endémica de les Balears, Consell Insular de Mallorca, FODESMA, Palma.

Ausín, I., Alonso-Blanco, C., and Martínez-Zapater, J. M., 2005: Environmental regulation of flowering, Int J Dev Biol, 49, 689705, doi: 10.1387/ijdb.052022ia.

Blionis, G. J., Halley, J. M., and Vokou, D., 2001: Flowering phenology of Campanula on Mt Olympos, Greece, Ecography, 24, 696-706.

Cuxart, J., Jiménez, M. A., and Martínez, D., 2007: Nocturnal Meso-Beta Basin and Katabatic Flows on a Midlatitude Island, Mon Weather Rev, 135, 918-932.

Cuxart, J., Jiménez, M. A., Telišman Prtenjak, M., and Grisogono, B., 2014: Study of a quasi-ideal sea breeze through momentum, temperature and turbulence budgets, J Appl Meteorol Climatol, in press.

Debussche, M., Garnier, E., and Thompson, J. D., 2004: Exploring the causes of variation in phenology and morphology in Mediterranean geophytes: a genus-wide study of Cyclamen, Bot J Linnean Soc, 145, 469-484.

Eppich, B., Dede, L., Ferenczy, A., Garamvölgyi, A., Horváth, L., Isépy, I., Priszter, S. Z., and Hufnagel, L., 2009: Climatic effects on the phenology of geophytes, Applied Ecology and Environmental Research, 7, 252-266.

Gresta, F., Avola, G., Lombardo, G. M., Siracusa, L., and Ruberto, G., 2009: Analysis of flowering, stigmas yield and qualitative traits of saffron (Crocus sativus) as affected by environment conditions, Sci Hortic, 119, 320-324, doi: 10.1016/j.scienta.2008.08.008.

Harpke, D., Meng, S., Rutten, T., Kerndorff, H., and Blattner, F. R., 2013: Crocus (Iridaceae) based on one chloroplast and two nuclear loci: Ancient hybridization and chromosome number evolution, Mol Phylogenet Evol, 66, 617-627, doi: 10.1016/j.ympev.2012.10.007.

Jiménez, M. A., Mira, A., Cuxart, J., Luque, A., Alonso, S., and Guijarro, J. A., 2008: Verification of a Clear-Sky Mesoscale Simulation Using Satellite-Derived Surface Temperatures, Mon Weather Rev, 136, 5148-5161.

Lobell, D. B., Cahill, K. N., and Field, C. B., 2007: Historical effects of temperature and precipitation on California crop yields, Clim Change, 81, 187-203, doi:10.1007/s10 584-006-9141-3.

Martínez, D., Jiménez, M. A., Cuxart, J., and Mahrt, L., 2010: Heterogeneous nocturnal cooling in a large basin under very stable conditions, Bound-Layer Meteor, 137, 97-113.

Mathew, B., 1984: Crocus L., Flora of Turkey and the East Aegean Islands, 8, Davis P.H. (ed.), University Press, Edinburgh, 413438.

Molina, R. V., Valero, M., Navarro, Y., García-Luis, A., and Guardiola, J. L., 2004: The effect of time of corm lifting and duration of incubation at inductive temperature on flowering in the saffron plant (Crocus sativus), Sci Hortic, 103, 79-91, doi: 10.1016/j.scienta.2004.04.008.

Molina, R. V., Valero, M., Navarro, Y., Guardiola, J. L., and García-Luís, A., 2005: Temperature effects on flower formation in saffron (Crocus sativus L.), Sci Hortic, 103, 361-370, doi: 10.1016/j.scienta.2004.06.005.

Morin, X., Lechowicz, M. J., Augspurger, C., O’Keefe, J., Viner, D., and Chuine, I., 2009: Leaf phenology in 22 North American tree species during the 21 st century, Glob Change Biol, 15, 961975.

Negb, M., Dagan, B., Dror, A., and Basker, D., 1989: Growth, flowering, vegetative reproduction, and dormancy in the saffron crocus (Crocus sativus L.), Israel J Bot, 38, 95-113.

Pastor-Férriz, M. T., Molina, R. V., García-Luis, A., de los MozosPascual, M., O.Satanas-Méridas, Rodríguez-Conde, M. F., Escolano-Tercero, M. A., Fernández, J. A., Medina-Alcázar, J., and Sanchís, E., 2013: Localización y caracterización del ambiente forestal en el que crecen las diferentes especies españolas del género Crocus, $6^{\circ}$ congreso forestal español, 6CFE01-062, 1-9.

Peñuelas, J., Filella, I., and Comas, P., 2002: Changed plant and animal life cycles from 1952 to 2000 in the Mediterranean region, Glob Change Biol, 8, 531-544.

Rosselló, J. A. and Castro, M., 2008: Karyological evolution of the angiosperm endemic flora of the Balearic Islands, Taxon, 57, 259-273.

Sakai, S., Harrison, R. D., Momose, K., Kuraji, K., Nagamasu, H., Yasunari, T., Choimng, L., and Nakashizuka, T., 2006: Irregular droughts trigger mass flowering in aseasonal tropical forest in Asia, Am J Bot, 93, 1134-1139.

von Willert, D. J., Eller, B. M., Werger, M. J. A., Brinckmann, E., and Ihlenfeldt, H. D., 1992: Life strategies of succulents in deserts, Cambridge University Press, Cambridge, 343pp, ISBN 0-521-24468-4. 